\title{
IL-3 is required for increases in blood basophils in nematode infection in mice and can enhance IgE-dependent IL-4 production by basophils in vitro
}

\author{
Chris S Lantz ${ }^{1}$, Booki Min², Mindy Tsai ${ }^{3}$, Devavani Chatterjea ${ }^{4}$, Glenn Dranoff ${ }^{5}$ and Stephen J Galli ${ }^{3}$
}

Basophils represent potential effector and immunoregulatory cells, as well as a potential source of IL-4, during the immune response elicited by infection with the nematode Nippostrongylus brasiliensis (N.b.), and in other settings. However, the factors which regulate the numbers of blood basophils in mice, or the ability of these cells to produce IL-4, are not fully understood. We found that infection of mice with the nematodes N.b. or Strongyloides venezuelensis (S.v.) induced substantial increases in the numbers of blood basophils (to as high as $18 \%$ of circulating blood leukocytes). Experiments in IL-3 $3^{-1-}$ vs IL-3 $3^{+/+}$mice, and in IL-3-treated IL-3 ${ }^{-/-}$mice, showed that essentially all of the increases in blood or bone marrow basophils during N.b. or S.v. infection were IL-3 dependent. Many of the blood, bone marrow or liver-derived basophils from IL-3 $3^{-/-}$or IL-3 ${ }^{+/+}$mice expressed intracellular IL-4 upon stimulation with anti-lgE in vitro. However, after incubation of the cells with exogenous IgE in vitro, blood- or liver-derived basophils from IL-3 $3^{+/+}$mice exhibited higher levels of intracellular IL-4 after stimulation with anti-lgE than did basophils derived from IL-3 $3^{-/-}$mice. Thus, IL-3 is a major regulator of the marked increases in blood basophil levels observed during infection of mice with N.b. or S.v. and also can enhance levels of intracellular IL-4 upon activation of basophils with anti-lgE in vitro.

Laboratory Investigation (2008) 88, 1134-1142; doi:10.1038/labinvest.2008.88; published online 22 September 2008

KEYWORDS: allergy; cytokines; immune response; inflammation; mast cells; parasites

Basophils have been characterized in the mouse, as well as in several other species, as bone marrow-derived granulocytes that circulate in the blood and can be recruited into tissues at sites of inflammation. ${ }^{1-6}$ Recent work has identified potential immunoregulatory functions of basophils as well. ${ }^{7-10}$ However, the factors that regulate the development and function of mouse basophils are not fully understood.

Both basophils and mast cells express the high affinity IgE receptor, FceRI, and can be activated to release IL-4 and other mediators upon aggregation of their FceRI by IgE and specific antigen. ${ }^{11-13}$ Moreover, we previously reported that nematode infections can substantially enhance the differentiation and the production of basophils in mice, as assessed by counting numbers of basophils in the bone marrow, as well as increase certain populations of tissue mast cells, by mechanisms that are largely or fully IL-3 dependent (for basophils) or partially IL-3 dependent (for mast cells). ${ }^{4}$ Nevertheless, several lines of evidence indicate that mouse basophils and mast cells represent distinct lineages ${ }^{4,5,14}$ and can have distinct roles in parasite infections, allergic disorders and other settings. ${ }^{4,5,7-10,14-18}$

During nematode infections $s^{2,5}$ and in models of allergic inflammation, ${ }^{16,19}$ mouse basophils represent a potentially significant source of IL-4, a cytokine that may help to sustain the Th2 responses in these models, as well as mediate other functions. ${ }^{15}$ Basophils also recently have been shown to be important for the development of hapten-specific chronic skin inflammation in transgenic mice, which express high amounts of hapten-specific IgE. ${ }^{7,8}$ Notably, increased amounts of IL-4 mRNA were detected in the skin lesions

\footnotetext{
${ }^{1}$ Department of Biology, James Madison University, Harrisonburg, VA, USA; ${ }^{2}$ Department of Immunology, Lerner Research Institute, Cleveland Clinic Foundation, Cleveland, OH, USA; ${ }^{3}$ Department of Pathology, Stanford University School of Medicine, Stanford, CA, USA; ${ }^{4}$ Department of Biology, Macalester College, Saint Paul, MN, USA and ${ }^{5}$ Department of Medical Oncology, Dana-Farber Cancer Institute, Harvard Medical School, Boston, MA, USA

Correspondence: SJ Galli, MD, Department of Pathology, Stanford University School of Medicine, 300 Pasteur Drive, Lane Building, L235, MC\# 5324, Stanford, CA 943055324, USA.

E-mail: sgalli@stanford.edu
}

Received 29 November 2007; revised 5 August 2008; accepted 6 August 2008 
associated with such IgE-induced chronic inflammation. ${ }^{7}$ However, it is not clear to what extent this reflected IL-4 mRNA in the basophils, as opposed to other cell types, present at these sites.

We previously showed that IL-3 is not necessary for the development of baseline levels of bone marrow basophils (or tissue mast cells) in the mouse, but that during nematode infections IL-3 is required for the expansion of numbers of bone marrow basophils, and contributes to the expansion of spleen and small intestinal mast cell populations. ${ }^{4}$ In vitro, IL-3 can significantly enhance Fc\&RI-dependent production of IL-4 by cell populations in which basophils represent the most likely source of IL- $4,{ }^{20}$ as well as FceRI-dependent activation and mediator secretion by mouse peritoneal mast cells $^{21}$ and human blood basophils. ${ }^{22-24}$ Thus, IL-3 produced during nematode infections may both regulate the size of two populations of effector cells that express FceRI (ie, basophils and mast cells), and also regulate the FceRI-dependent secretory function of these cells.

However, past studies of mouse basophils primarily quantified these cells in the spleen, ${ }^{25,26}$ bone marrow, ${ }^{4,26}$ lung ${ }^{5,25,26}$ or liver, ${ }^{25,26}$ and used exogenous IL-3 to investigate whether this cytokine influenced basophil IL-4 production in vitro. ${ }^{20}$ This work indicated that infection with Nippostrongylus brasiliensis (N.b.) can result in increases in populations of basophils, ${ }^{4,5,25,26}$ including in the blood, ${ }^{5,25,26}$ and that exogenous IL-3 can increase levels of basophils in wild-type mice. ${ }^{25,27}$ In the present study, we used IL- $3^{-1-}$ and $\mathrm{IL}-3^{+/+}$mice, and IL-3-treated $\mathrm{IL}-3^{-1-}$ mice, to investigate the potential role of IL-3 in regulating blood basophil levels in mice and assessed whether basophils from IL-3 $3^{-/-}$mice exhibited any impairment in their ability to produce IL-4 upon stimulation by the FceRI in vitro.

\section{MATERIALS AND METHODS}

\section{Mice and Nematode Infection}

$\mathrm{BALB} / \mathrm{c}$ and $\mathrm{C} 57 \mathrm{BL} / 6 \mathrm{~J}$ mice, 8-13 weeks of age, were obtained from Charles River Laboratory, Wilmington, MA, USA, and the Jackson Laboratory, Bar Harbor, ME, USA for experiments conducted at the Beth Israel Deaconess Medical Center, from the Laboratory Animal Breeding Colony at Stanford University for experiments conducted at Stanford, and from the Jackson laboratory for the experiments conducted at the Cleveland Clinic. IL- $3^{-/-}$and their wild-type littermates (IL- $3^{+/+}$) were backcrossed for at least nine generations onto $\mathrm{C} 57 \mathrm{BL} / 6$ or $\mathrm{BALB} / \mathrm{c}$ mice. ${ }^{28}$ Some mice were infected by subcutaneous inoculation with 500 or 800 N.b. larvae ${ }^{29}$ or 2000 Strongyloides venezuelensis (S.v.) larvae. ${ }^{4}$ The degree of infection of individual mice was monitored by counting the numbers of eggs excreted daily (eggs per $\mathrm{g}$ feces) and/or, at the time of killing, the numbers of adult intestinal worms. S.v. and N.b. were maintained by serial passage in male Wistar rats or female BALB/c mice, respectively. All animal care and experimentation were conducted according to guidelines of the National Institutes of Health and the
Beth Israel Deaconess Medical Center, Stanford University, or Cleveland Clinic Institutional Animal Care and Use Committees.

\section{Identification and Quantification of Mouse Basophils}

Mouse blood and bone marrow cells were isolated from the orbital sinus and femurs, and RBCs were lysed with Trisbuffered ammonium chloride. Cells were incubated with B3B4 and 2.4G2 mAbs for $15 \mathrm{~min}$ to block low affinity binding of IgE or other subsequent Abs to CD23 or Fc $\gamma$ RII/ III, respectively, followed by sensitization with mouse IgE mAb (Sigma Chemical Company, St Louis, MO, USA; clone SPE-7) for $50 \mathrm{~min}$. Cells were washed and stained with FITC anti-IgE (clone R35-72) and PE anti-CD45R/B220 (clone RA3-6B2) mAbs for $25 \mathrm{~min}$. For detection of c-kit, cells were incubated for $25 \mathrm{~min}$ with biotinylated anti-c-kit $\mathrm{mAb}$ (clone 2B8) followed by PE-streptavidin. Except for the SPE-7 IgE $\mathrm{mAb}$, all Abs listed above, including appropriate isotypematched controls, were obtained from Pharmingen, San Diego, CA, USA, and used at $10 \mu \mathrm{g} / \mathrm{ml}$ on ice. In some experiments, we sought to identify basophils without using antibodies to IgE or FceRI. For these experiments, blood or liver cells were obtained as described in detail in $^{26}$ and basophils in those populations were identified as described in, ${ }^{26,30}$ by staining with FITC-labeled anti-CD16/32 (clone 93) and APC-labeled anti-CD45 (30-F11; these Abs, and isotype-matched controls, were obtained from eBioscience, San Diego, CA, USA, and used at $10 \mu \mathrm{g} / \mathrm{ml}$ on ice). In such experiments, some cells were incubated ex vivo with an antiTNP IgE mAb (IgE-3) and/or stimulated with anti-IgE (R3572). Stained cells were analysed using a FACSCalibur ${ }^{\circledR}$ with CellQuest ${ }^{\circledR}$ (Becton Dickinson, San Jose, CA, USA) or FlowJo (Ashland, OR, USA) software. The number of basophils per $\mathrm{mm}^{3}$ blood was calculated by multiplying the percentage of basophils (as determined by flow cytometry) by the total WBC count. For light microscopic examination, cells were sorted using a FACSVantage ${ }^{\circledR}$ (Becton Dickinson), cytocentrifuged onto slides, and stained $6 \mathrm{~h}$ with $1.0 \%$ alcian blue at $\mathrm{pH} 1.0$ followed by safranin for $10 \mathrm{~min}$.

\section{Treatment with IL-3 In Vivo}

Male S.v.-infected IL- $3^{+/+}$and IL- $3^{-/-}$mice received twice daily i.p. injections of IL-3 (140 ng/day, from supernatants conditioned by B16-F10 murine melanoma cells that were genetically engineered to produce mouse IL- $3^{31}$ ) or vehicle beginning on day 5 of infection. IL-3 concentration was measured by ELISA (Endogen, Cambridge, MA, USA). Mice were killed the day each cleared their individual infection (Figure $3 \mathrm{~b}$ and $\mathrm{c}$ ) or, in a separate experiment, on day 13 of infection (Figure 3a). To quantify mast cells, $4 \mu \mathrm{m}$ paraffin sections of Carnoy's-fixed tissues were stained with safranin and $1.0 \%$ alcian blue at $\mathrm{pH} 0.3$ (or $\mathrm{pH} 1.0$ for spleen) and mast cells were counted as the number per $\mathrm{mm}^{2}$ of spleen, or for jejunum and ileum, as the number per villus crypt unit. 


\section{Basophil Activation and Staining of Intracellular IL-4 for Flow Cytometric Analysis}

Two approaches were used for these experiments. In the first method, blood and bone marrow cells from IL-3 $3^{+1+}$ and IL- $3^{-/-}$mice were depleted of RBCs, pooled according to genotype, and sensitized with mouse IgE $\mathrm{mAb}$ for $50 \mathrm{~min}$ on ice (without B3B4 and 2.4G2 mAbs). Cells were washed, and incubated for $5 \mathrm{~h}$ at $37^{\circ} \mathrm{C}$ in complete DMEM containing Brefeldin A (Sigma; $10 \mu \mathrm{g} / \mathrm{ml})$ and FITC anti-IgE $(10 \mu \mathrm{g} / \mathrm{ml})$. This step served simultaneously to activate and fluorescently stain $\mathrm{Fc}_{\varepsilon} \mathrm{RI}^{+}$basophils, and to allow IL-4 to accumulate within the ER and/or Golgi complex. Cells were fixed for 10 min with $4 \%$ paraformaldehyde in $\mathrm{PBS}$ at $37^{\circ} \mathrm{C}$, permeabilized on ice for $15 \mathrm{~min}$ with PBS containing $0.1 \%$ saponin, $2.4 \mathrm{G} 2 \mathrm{mAb}(10 \mu \mathrm{g} / \mathrm{ml})$, and $2 \% \mathrm{FCS}$, and stained for $25 \mathrm{~min}$ on ice with PE anti-IL-4 mAb (clone 11B11, at $2 \mu \mathrm{g} / \mathrm{ml}$ ) in PBS containing 2\% FCS. Many negative controls, all of which yielded similar results, were used to establish flow cytometry gates. As one control, IgE-sensitized cells were incubated with FITC $\operatorname{IgG}_{1}$ (clone R3-34, as an FITC-labeled antibody of irrelevant antigen specificity) for $5 \mathrm{~h}$ at $37^{\circ} \mathrm{C}$ with Brefeldin $\mathrm{A}$ followed by staining with FITC anti-IgE $(10 \mu \mathrm{g} / \mathrm{ml}) \mathrm{mAb}$ on ice for $25 \mathrm{~min}$. Specificity of IL-4 staining was demonstrated both by preincubating cells with excess unlabeled anti-IL-4 $\mathrm{mAb}(60 \mu \mathrm{g} / \mathrm{ml})$, and by staining cells with a PE isotypematched control mAb (clone R3-34). Except for IgE, all Abs were purchased from Pharmingen.

A second approach was used to analyse basophils without using FITC anti-IgE to identify the basophils by FACS. This permitted us to avoid activating the basophils by the FceRI except at the time we wished to stimulate some of these cells in vitro. Groups of wild-type BALB/c (IL- $3^{+/+}$) and BALB/c IL- $3^{-I-}$ mice were subcutaneously infected with 500 N.b. larvae and mice were killed 10 days postinfection. Blood and liver cells were incubated with or without $5 \mu \mathrm{g} / \mathrm{ml}$ of a mouse IgE $\mathrm{mAb}$ (IgE-3, anti-TNP) for $50 \mathrm{~min}$ on ice and subsequently incubated with or without $1 \mu \mathrm{g} / \mathrm{ml}$ anti-IgE (R35-72) for an additional $4 \mathrm{~h}$ at $37^{\circ} \mathrm{C}$. Monensin $(2 \mu \mathrm{M})$ was added during the last $2 \mathrm{~h}$ of incubation. Cells were harvested, fixed, and stained for surface expression of FITC-labeled anti-CD16/32 (clone 93), APC-labeled anti-CD45 (30-F11), and PE-labeled anti-IL-4 (11B11) for $45 \mathrm{~min}$. Cells were acquired using a FACSCalilbur and analysed using FlowJo software.
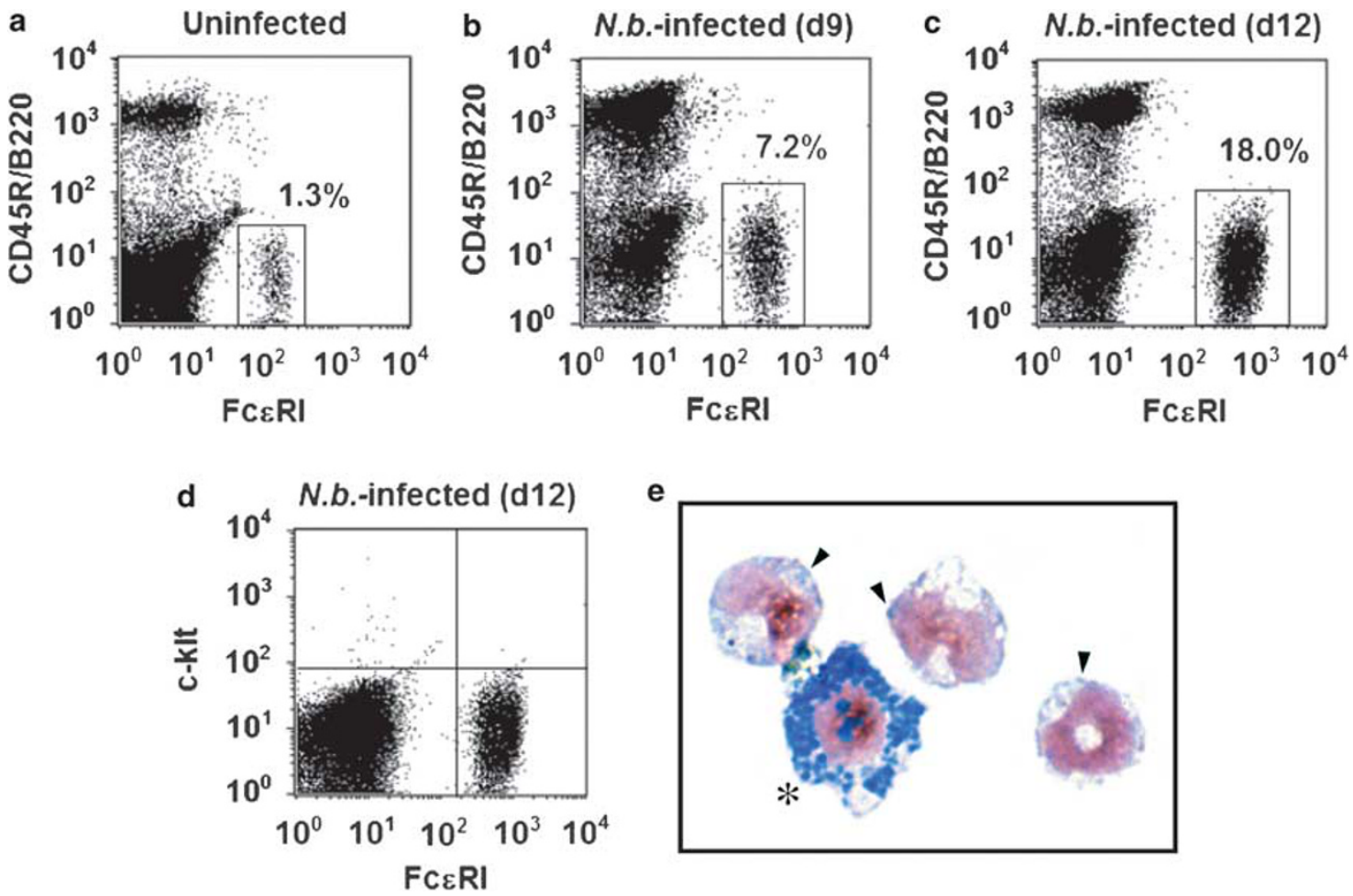

Figure 1 Blood basophils are markedly increased following infection with N.b. (800 larvae, subcutaneously). Blood cells from uninfected (a) and N.b.infected (b-e) female BALB/c mice were stained for Fc\&RI and CD45R/B220 (a-c) or c-kit (d). Representative FACS plots from individual mice indicate the percentage of blood basophils at baseline (a; basophils per $\mathrm{mm}^{3}$ blood $=47 \pm 3 ; n=4$ ), and at day 9 (b; basophils per $\mathrm{mm}^{3}$ blood $=284 \pm 35 ; n=5$ ) and 12 (c) $\mathbf{d}$; basophils per $\mathrm{mm}^{3}$ blood $=787 \pm 89 ; n=4$ ) after infection. Few c-kit ${ }^{+}$cells were detectable above background at day 12 (d) or at other time periods examined (a-c, data not shown). The $\mathrm{F} c \varepsilon \mathrm{RI}^{+}, \mathrm{CD} 45 \mathrm{R} / \mathrm{B} 220^{-}$cells in (c) were sorted, stained with alcian blue and safranin, and found microscopically to consist predominantly (95\%) of cells with a polylobed nucleus (e). Ninety seven percent of these cells contained small numbers of granules that stained lightly with alcian blue (arrowheads). One mast cell $\left(^{*}\right)$ was observed among multiple slides examined. Similar results were obtained in two other experiments using BALB/c mice. 


\section{Statistics}

Unless otherwise specified, all data are expressed as the mean \pm s.e.m., and all differences between values were compared using the unpaired two-tailed Student's $t$-test.

\section{RESULTS}

Mouse Blood Basophil Levels are Markedly Increased Following Infection with N.b.

Blood cells obtained from 8 to 13 -week-old $\mathrm{BALB} / \mathrm{c}$ mice were stained for the expression of B220 and FceRI. The percentage of $\mathrm{B} 220^{-}, \mathrm{Fc}_{\mathrm{R}} \mathrm{RI}^{+}$cells identified as basophils by flow cytometric analysis, as well as alcian blue/safranin staining in the blood, showed a marked increase above baseline (Figure 1a) in mice infected with N.b.; a 7-fold increase 9 days after infection with 800 parasites (Figure 1b) and an 18-fold increase 12 days after infection (Figure 1c). Few or no c-kit-expressing mast cells were detected in the blood at any time, including at 12 days after infection (Figure 1d). The $\mathrm{B} 220^{-}, \mathrm{Fc}_{\varepsilon} \mathrm{RI}^{+}$cell population was sorted and stained with alcian blue/safranin. Ninety five percent of these cells had a polylobed nucleus and $97 \%$ contained small granules that stained lightly with alcian blue (Figure 1e). By contrast, only a single cell with the morphological characteristics of a mast cell was found in all of the slides of blood examined $\left({ }^{*}\right.$ in Figure 1e). Similar results were obtained in two other experiments using BALB/c mice (data not shown).

\section{IL-3 is Required for the Development of Increased Numbers of Blood and Bone Marrow Basophils in Parasite-Infected Mice}

Basophils per $\mathrm{mm}^{3}$ of blood were approximately threefold higher than baseline levels 9 days after S.v. infection and more than fivefold higher 11 days after N.b. infection in C57BL/6-IL- $3^{+/+}$mice, whereas C57BL/6-IL-3 ${ }^{-1-}$ mice had levels of blood basophils that were unchanged or even lower than baseline following parasite infection (Figure 2a). The percent of bone marrow basophils in mice of the two genotypes showed an identical pattern of change following infection with N.b. and S.v. larvae (Figure 2b); levels of bone marrow basophils increased to two- and threefold baseline levels 9 and 11 days after S.v. and N.b. infection, respectively, in $\mathrm{IL}-3^{+1+}$ mice although they remained unchanged or at lower than baseline levels in the bone marrow of $\mathrm{IL}-3^{-1-}$ mice at those time points. Both $\mathrm{IL}-3^{+1+}$ and $\mathrm{IL}-3^{-1-}$ N.b.-infected mice cleared their infection by day 11 and there was no statistically significant difference between the numbers of adult S.v. worms 9 days after infection in IL-3 $3^{+1+}$ and IL- $3^{-1-}$ mice (adult worms per small intestine: $\mathrm{IL}^{-} 3^{+/+}$, $145 \pm 15$ vs $\left.\mathrm{IL}-3^{-1-}, 230 \pm 68 ; P=0.31\right)$. Thus, the IL-3 deficiency did not affect parasite clearance in N.b.-infected mice or numbers of adult worms or egg production at day 9 in S.v.-infected mice, but IL-3 was required for the expansion of blood basophils following parasite infection. By contrast, IL-3 was not required for the maintenance of baseline levels of bone marrow or blood basophils in naïve mice.
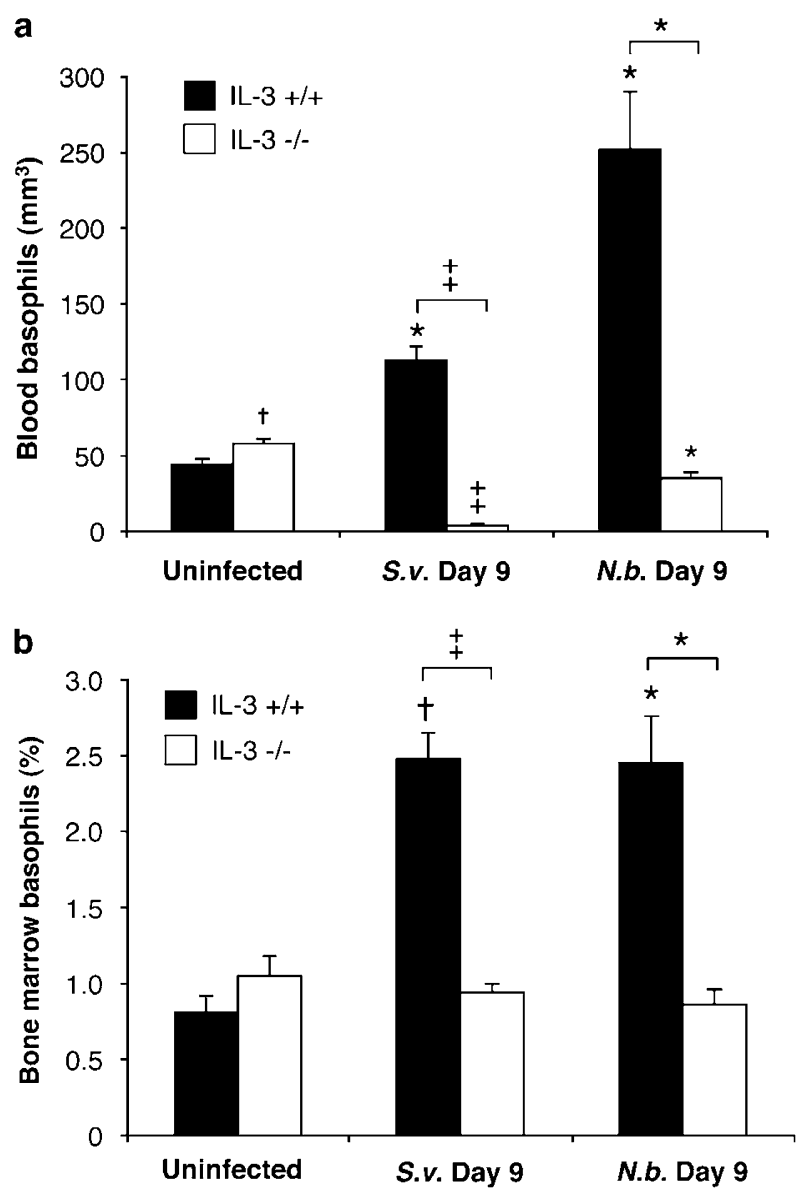

Figure 2 IL-3 is required for increased numbers of blood and bone marrow basophils in parasite-infected mice. Levels of blood (a) and bone marrow (b) basophils from $\mathrm{C} 57 \mathrm{BL} / 6-\mathrm{IL}-3^{+/+}$and IL-3 $3^{-1-}$ mice were examined at baseline, and after infection with S.v. (2000 larvae, subcutaneously) and N.b. (800 larvae, subcutaneously) for 9 and 11 days, respectively. There was no statistically significant difference between the number of adult S.v. worms at day 9 of infection in IL-3 $3^{+/+}$and IL- $3^{-/-}$mice (see text). All N.b.-infected mice cleared their infection by day 11 . All values are mean \pm s.e.m. $(n=3-5$ mice per group). ${ }^{*}$ indicates $P<0.05 ;{ }^{\dagger} P<0.001 ;{ }^{\ddagger} P<0.0001$ vs corresponding baseline values or (as indicated by the square brackets) vs corresponding values for mice of the other genotype. Similar results were obtained in three other experiments using C57BL/6- or BALB/C-IL-3 $3^{+1+}$ and $\mathrm{IL}-3^{-1-}$ mice infected with S.v. (one experiment, 2000 larvae, subcutaneously) or N.b. (two experiments, 800 larvae, subcutaneously).

\section{Treatment of S.v.-Infected IL-3 ${ }^{-1-}$ Mice with Exogenous IL-3 Restores Basophil and Tissue Mast Cell Numbers to Levels That are Similar to Those Observed in S.v.-Infected IL-3 ${ }^{+I+}$ Mice}

Intraperitoneal injection twice daily of IL-3 (total of $140 \mathrm{ng} /$ day) into male $\mathrm{IL}-3^{-1-}$ mice during infection with S.v. restored blood and bone marrow basophil levels, as well as mast cell numbers in the spleen and ileum, to values that were statistically indistinguishable from those observed in S.v.-infected IL-3 $3^{+/+}$mice (Figure 3). IL-3 treatment also markedly increased numbers of mast cells in the jejunum of S.v.-infected IL- $3^{-1-}$ mice (Figure 3c). Although the effects 
a

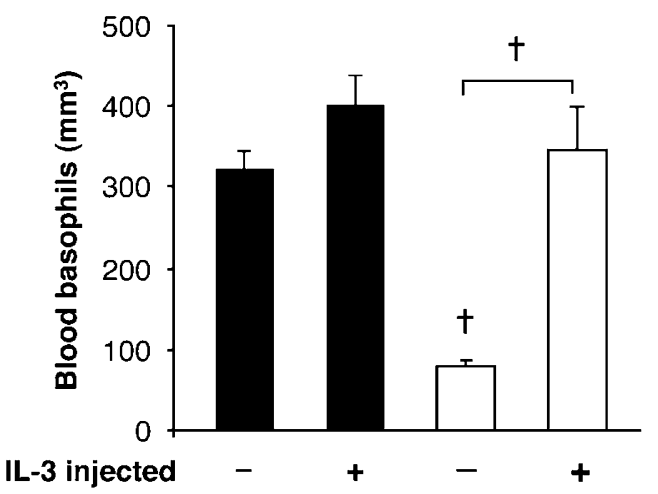

b

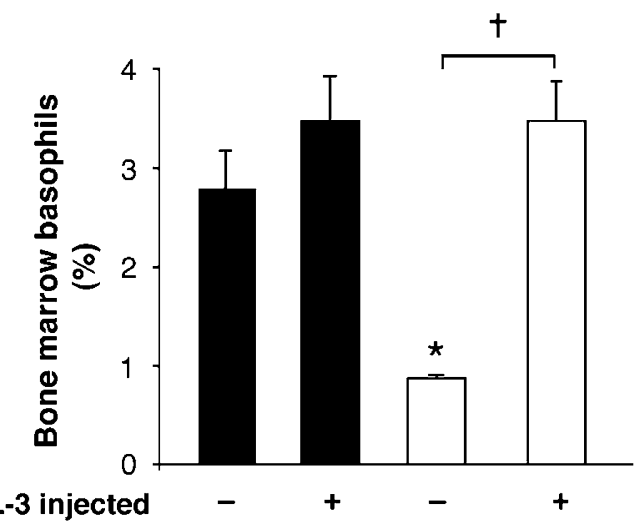

c

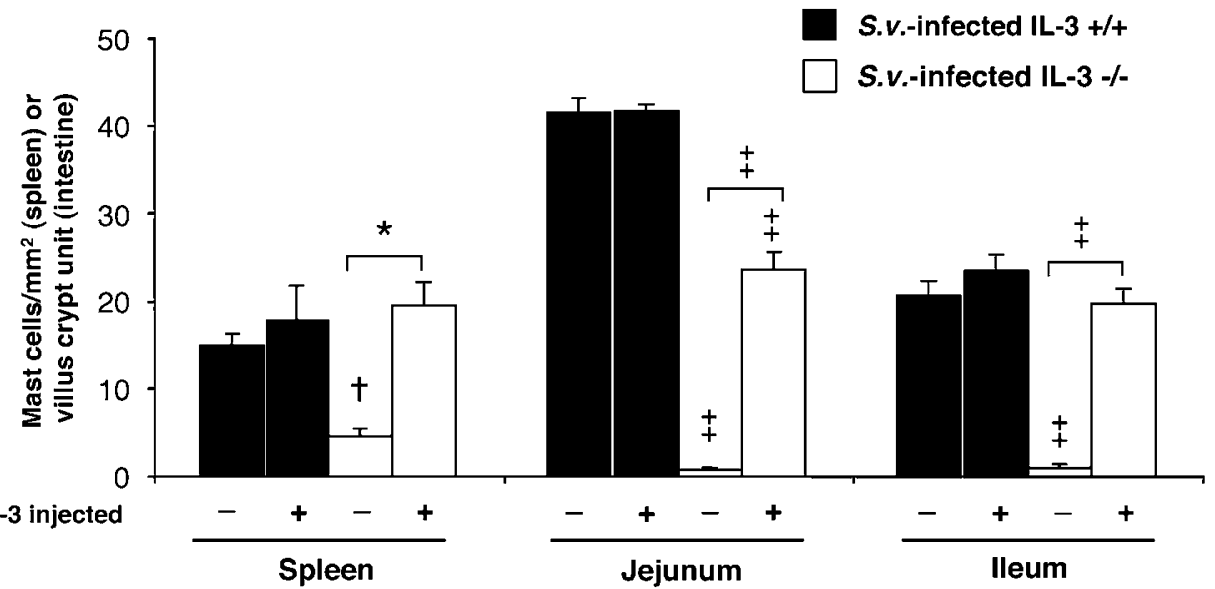

Figure 3 Treatment of S.v.-infected (2000 larvae, subcutaneously) male C57BL/6 IL-3 $3^{-1-}$ mice with exogenous IL-3 restores basophil and tissue mast cell numbers to levels that are similar to those observed in S.v.-infected (2000 larvae, subcutaneously) C57BL/6 IL- $3^{+/+}$mice. Blood (a) and bone marrow (b) basophil, and tissue mast cell (c) levels were examined in IL-3- or vehicle-treated S.v.-infected male IL- $3^{+/+}$and IL- $3^{-/-}$mice on the day of clearance of infection (b, $\mathbf{c}$; days 12-16) or, in a separate experiment (a), at the time the IL $-3^{+/+}$mice cleared their infection (day 13). All values are mean \pm s.e.m. ( $n=3-6$ mice per group). ${ }^{*}$ indicates $P<0.05 ;{ }^{\dagger} P<0.001 ;{ }^{\ddagger} P<0.0001$ vs corresponding values for mice of the other genotype or (as indicated by the square brackets) $v s$ values for mice of the same genotype.

were not statistically significant, injection of IL-3 in S.v.-infected IL-3 $3^{+1+}$ animals may have resulted in slight increases in levels of blood and bone marrow basophils, and perhaps in some mast cell populations (Figure 3).

\section{IL-3 is not Required for, but can Enhance, IL-4 Production by Blood or Bone Marrow Basophils Following Fc\&RI Cross-Linkage In Vitro}

Although IL-3 ${ }^{-1-}$ mice did not exhibit increases in blood or bone marrow basophils following infection with N.b. or S.v., we found that IL-3 was not required for production of intracellular IL-4 following FceRI cross-linkage in vitro in blood or bone marrow basophils derived from either normal or N.b.-infected mice. As assessed by intracellular cytokine staining, freshly isolated blood and bone marrow basophils produced IL-4 after activation by FITC anti-IgE mAb in vitro, whether the cells were derived from C57BL/6 $\mathrm{IL}-3^{+/+}$or IL- $3^{-I-}$ mice (Figure 4). In uninfected IL- $3^{-/-}$and IL- $3^{+/+}$ mice, basophils represented $\sim 1.5 \%$ of total blood leukocytes and $\sim 1.0 \%$ of total bone marrow cells. After incubation with mouse IgE followed by challenge with FITC anti-IgE in vitro, $\sim 45-52 \%$ of the blood basophils and $\sim 10 \%$ of the bone marrow basophils were IL- $4^{+}$. The differences in the levels of IL-4 producing cells within the bone marrow and blood basophil populations may reflect, at least in part, the fact that circulating basophils in the periphery are, as a population, more mature developmentally than is the bone marrow population, which includes multiple developmental stages.

In blood leukocytes that were obtained from N.b.-infected C57BL/6 mice and then were incubated with IgE and FITC anti-IgE in vitro, $80 \%$ of $\mathrm{IL}-3^{-/-}$and $95 \%$ of $\mathrm{IL}-3^{+/+}$blood basophils were IL- $4^{+}$and $47 \%$ of IL- $3^{-1-}$ or IL- $3^{+/+}$bone marrow basophils were IL- $4^{+}$(Figure 4 ). As shown in Figures 2 and $4, \mathrm{IL}^{-} 3^{-1-}$ mice had a significant defect in nematode-induced basophil hyperplasia. In Figure 4, 10.7\% of total blood leukocytes in IL-3 ${ }^{+1+}$ mice were basophils vs only $1.3 \%$ in the IL-3-deficient counterparts. For bone marrow basophils, the corresponding values were $2.6 \%$ in $\mathrm{IL}^{-} 3^{+1+}$ mice $v s \quad 0.8 \%$ in IL-3 $3^{-/-}$mice (Figure 4). Such experiments showed that, under the conditions tested, a lack 


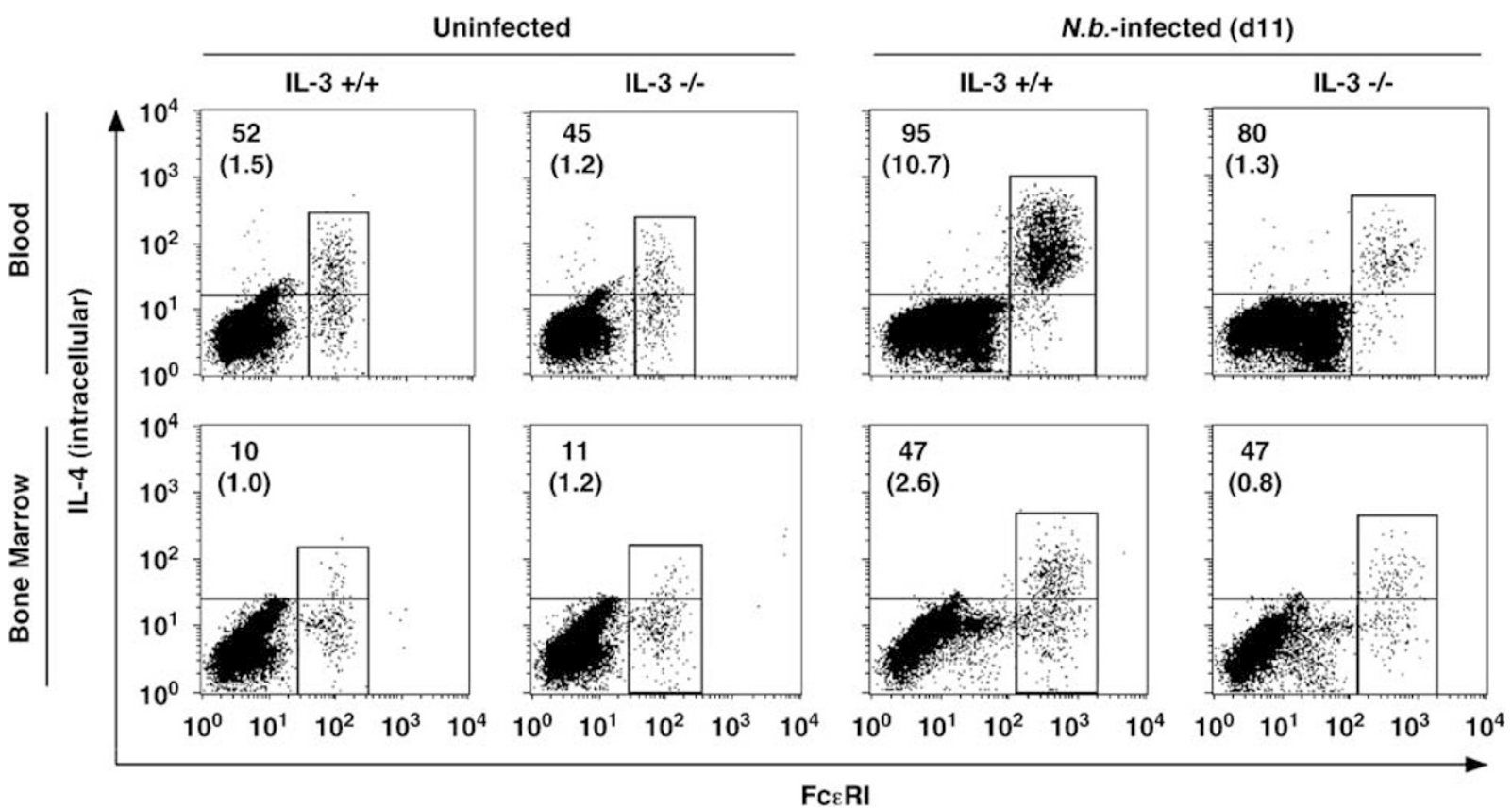

Figure 4 IL-3 is not required for blood or bone marrow basophils from uninfected or N.b.-infected C57BL/6-IL- $3^{+/+}$or IL- $3^{-/-}$mice to produce IL-4 after $\mathrm{Fc} \varepsilon \mathrm{RI}$ cross-linkage in vitro. Freshly isolated blood and bone marrow cells from uninfected or N.b.-infected (800 larvae, subcutaneously) C57BL/6-IL-3 $3^{+/+}$and IL- $3^{-/-}$mice ( $n=3-4$ mice per group; day 11 of infection) were pooled, incubated on ice $+\operatorname{lgE}$ for 50 min, followed by stimulation for $5 \mathrm{~h}$ at $37^{\circ} \mathrm{C}$ with FITClabeled anti-lgE mAb in the presence of Brefeldin A. Basophils, identified as Fc\&RI ${ }^{+}$cells, were examined for intracellular IL-4 production by FACS. Fc $\varepsilon \mathrm{RI}^{+}$ basophils are located in either the upper right $\left(\mathrm{IL}-4^{+}\right)$or lower right $\left(\mathrm{IL}-4^{-}\right)$quadrants. The first number in each plot represents the percentage of IL-4 ${ }^{+}$ basophils. The number in parenthesis represents the percentage of basophils in the total cell population. Gates were established using negative controls (see 'Materials and methods' section). Similar results were obtained in another experiment using IL- $3^{+/+}$and IL-3 $3^{-1-}$ mice.

of IL-3 does not eliminate the IL-4 production capacity of mouse basophils after anti-IgE stimulation in vitro.

We also examined intracellular IL-4 production in basophils that were analysed by FACS without using antibodies to IgE or FceRI to identify the cells. ${ }^{26}$ Blood cells were pooled from $\mathrm{BALB} / \mathrm{c}$ IL- $3^{-1-}$ and IL- $3^{+/+}$mice $(n=3-4$ in each group) on day 10 of N.b. infection. Duplicate aliquots of these blood leukocytes were then incubated for $50 \mathrm{~min}$ on ice $\pm \operatorname{IgE}$ and then stimulated for $4 \mathrm{~h}$ with anti-IgE, with monensin added for the last $2 \mathrm{~h}$; negative control cells were incubated under the same conditions but without exogenous IgE or anti-IgE.

Little intracellular IL-4 was detectable in basophils incubated in vitro with neither exogenous $\operatorname{IgE}$ nor anti-IgE (Figure 5). However, anti-IgE stimulation of cells which had not been incubated with additional $\operatorname{IgE}$ in vitro induced similar percentages of IL-3 $3^{+/+}$or IL- $3^{-/-}$basophils (41-54\%) to exhibit intracellular staining for IL-4 (Figure 5). By contrast, after incubation with exogenous IgE in vitro before activation with anti-IgE, blood basophils from IL- $3^{+/+}$mice exhibited substantially higher levels of intracellular staining for IL-4 than did the corresponding cells from IL- $3^{-1-}$ mice (Figure 5). Similar results were obtained in a separate experiment analyzing $\mathrm{IL}-3^{+/+}$s $\mathrm{IL}-3^{-/-}$mouse blood basophils that had been incubated with exogenous IgE before stimulation with anti-IgE in vitro. Using data pooled from the latter experiment and the experiment shown in Figure 5, we analysed the percentage of IL-3 $3^{+1+} v s$ IL-3 $3^{-1-}$ blood basophils that stained for intracellular IL-4, and the MFI of IL-4 staining in blood basophils (Figure 6a). Incubation with exogenous IgE before stimulation with anti-IgE resulted in a significantly higher percentage of basophils that exhibited intracellular staining with IL-4, and a significantly higher MFI of such staining, in blood basophils derived from $\mathrm{IL}_{-} 3^{+/+}$vs $\mathrm{IL}-3^{-/-}$mice.

We also analysed intracellular IL-4 production following $e x$ vivo stimulation in basophils isolated from the liver of N.b. infected mice. As more basophils can be obtained from the livers than the blood of such mice, we individually tested the liver basophils obtained from IL-3 ${ }^{+1+}(n=4)$ mice and from IL- $3^{-I-}$ mice $(n=3)$. As shown in Figure $6 \mathrm{~b}$, the results obtained with liver-derived basophils were very similar to those obtained in tests of blood basophils (Figure 6a). Only low levels of intracellular IL-4 were detected in basophils incubated without exogenous $\mathrm{IgE}$ or anti-IgE $\left(\mathrm{MFI}=16.2 \pm 1.1\right.$ vs $18.8 \pm 1.6$ for $\mathrm{IL}-4^{+}$basophils derived from IL-3 $3^{+/+} v s \mathrm{IL}-3^{-1-}$ mice $\left.(P>0.05)\right)$, higher levels of intracellular IL-4 were detected in anti-IgE stimulated basophils, which had not been incubated with exogenous IgE in vitro $\left(\mathrm{MFI}=35.9 \pm 1.2\right.$ vs $30.9 \pm 2.5$ for $\mathrm{IL}-4^{+} \mathrm{IL}-3^{+/+}$vs IL- $^{-1-}$ cells $\left.(P>0.05)\right)$, and, after incubation with exogenous IgE in vitro, these responses were even stronger in 
a
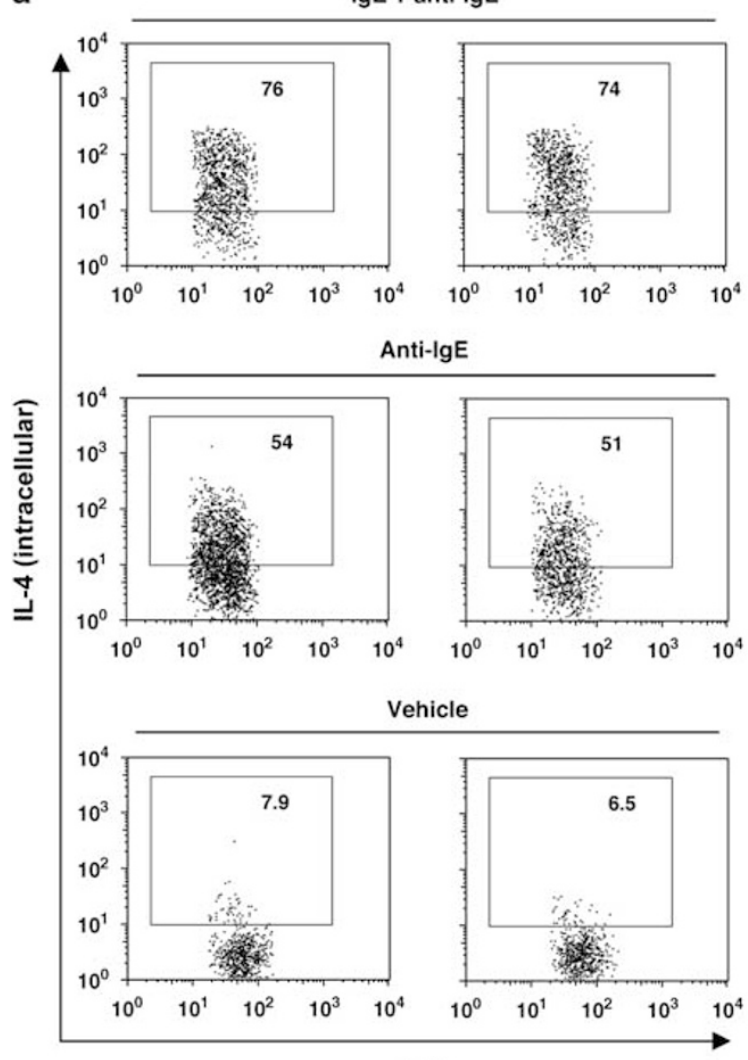

FcyR b
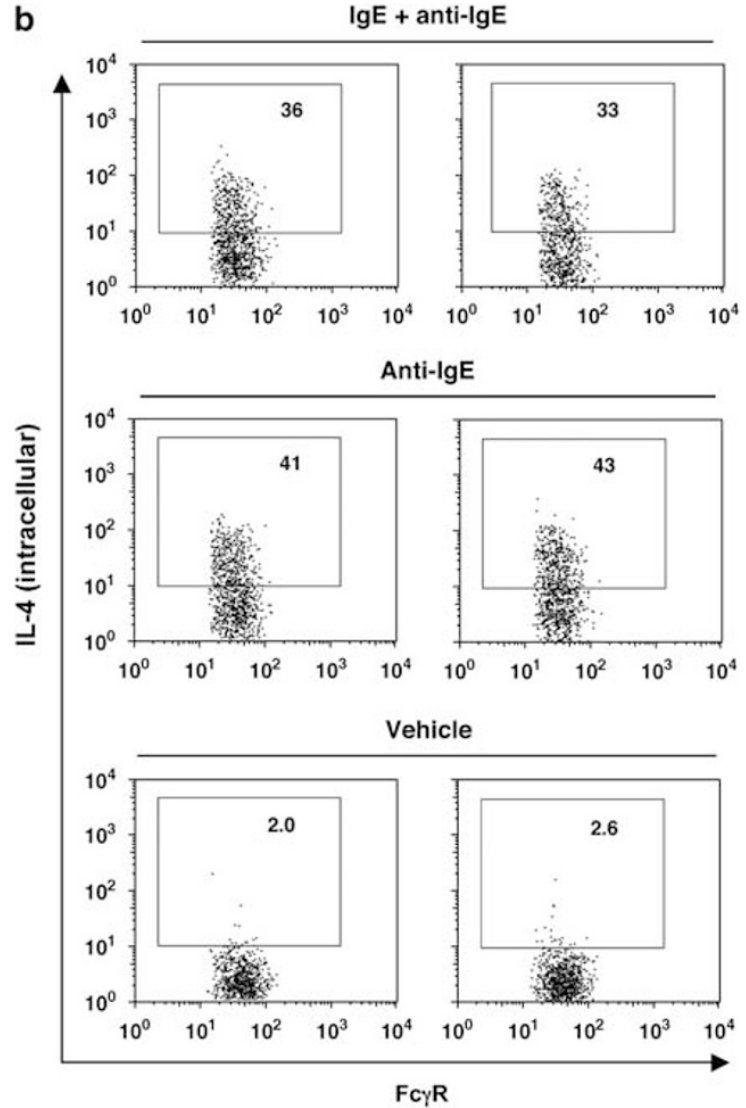

Figure $5 \mathrm{IL}-3$ is not required for blood basophils from N.b.-infected BALB/c-IL-3 $3^{+/+}$(a) or IL-3 ${ }^{-/-}$(b) mice to produce IL-4 after FceRI cross-linkage in vitro. Freshly isolated blood leukocytes from N.b.-infected (500 larvae, subcutaneously) BALB/c IL-3 ${ }^{+/+}$and IL- $3^{-1-}$ mice $(n=3-4$ mice per group) were obtained on day 10 of infection, pooled, and divided into two aliquots. The cells were then incubated on ice $\pm \operatorname{lgE}$ for 50 min, followed by stimulation for $4 \mathrm{~h}$ at $37^{\circ} \mathrm{C}$ with anti-IgE $\mathrm{mAb}$, the last $2 \mathrm{~h}$ in the presence of monensin. Basophils, identified as $\mathrm{Fc \gamma} \mathrm{R}^{+}, \mathrm{CD}_{4} 5^{+}$cells, were examined for intracellular IL-4 production by FACS. The number in each plot represents the percentage of $\mathrm{IL}_{-} 4^{+}$basophils.

anti-IgE stimulated basophils from IL-3 $3^{+1+}$ mice but not in the identically treated basophils from $\mathrm{IL}-3^{-1-}$ mice $\left(\mathrm{MFI}=47.9 \pm 1.9\right.$ vs $26.7 \pm 1.7$ for $\mathrm{IL}-3^{+/+}$vs $\mathrm{IL}-3^{-/-}$cells $(P<0.005))$.

Taken together, the data in Figures 4-6, obtained using basophils derived from IL- $3^{+/+} v s$ IL- $3^{-/-}$mice on either the $\mathrm{C} 57 \mathrm{BL} / 6$ (Figure 4) or BALB/c (Figures 5 and 6) backgrounds, indicate that basophils derived from IL- $3^{-/-}$mice can produce intracellular IL-4 upon activation by $\operatorname{IgE}$ and FceRI in vitro, but that such responses can be enhanced in basophils derived from IL- $3^{+/+}$mice.

\section{DISCUSSION}

Our findings show that IL-3 is required for the striking increases in blood basophils that occur in C57BL/6 or BALB/C mice during infection with either N.b. or S.v. in vivo. By contrast, IL-3 appears to be largely dispensable for maintaining the low levels of blood basophils observed in the circulation of uninfected mice. These finding are in accord with our observation that IL-3 is required for the increases in bone marrow basophils associated with S.v. or N.b. infection in mice, but is not required for maintaining low levels of bone marrow basophils in uninfected animals. ${ }^{4}$ While the present study was under review, Shen et $a^{26}$ also found, using $\mathrm{BALB} / \mathrm{c} \mathrm{IL}-3^{-1-}$ vs IL-3 $3^{+1+}$ mice, that IL-3 was required for the increases in numbers of basophils in the blood, bone marrow, and liver in BALB/c mice infected with N.b., and provided evidence that $\mathrm{T}$ cells represent an important source of such IL-3 in this setting.

Khodoun et $a l^{27}$ showed that the administration of IL-3 to IL-3 sufficient mice can result in expanded basophil populations in the spleen of naïve wild-type mice. ${ }^{27}$ We found that administration of recombinant IL-3 beginning on day 5 of S.v. infection permitted IL- $3^{-1-}$ mice to exhibit numbers of blood and bone marrow basophils, as well as mast cells in the spleen and ileum, that were statistically indistinguishable from those observed in S.v.-infected IL- $3^{+/+}$mice. These findings support the conclusion that the striking abnormalities in basophil and mast cell numbers that occur during nematode infection in IL- $3^{-1-}$ mice reflect the lack of IL-3 in the adult animals, rather than the consequences of a developmental problem, related to the genetic deficiency in IL-3, that irreversibly alters the responsiveness of the basophil or mast cell lineages to IL-3. 
a
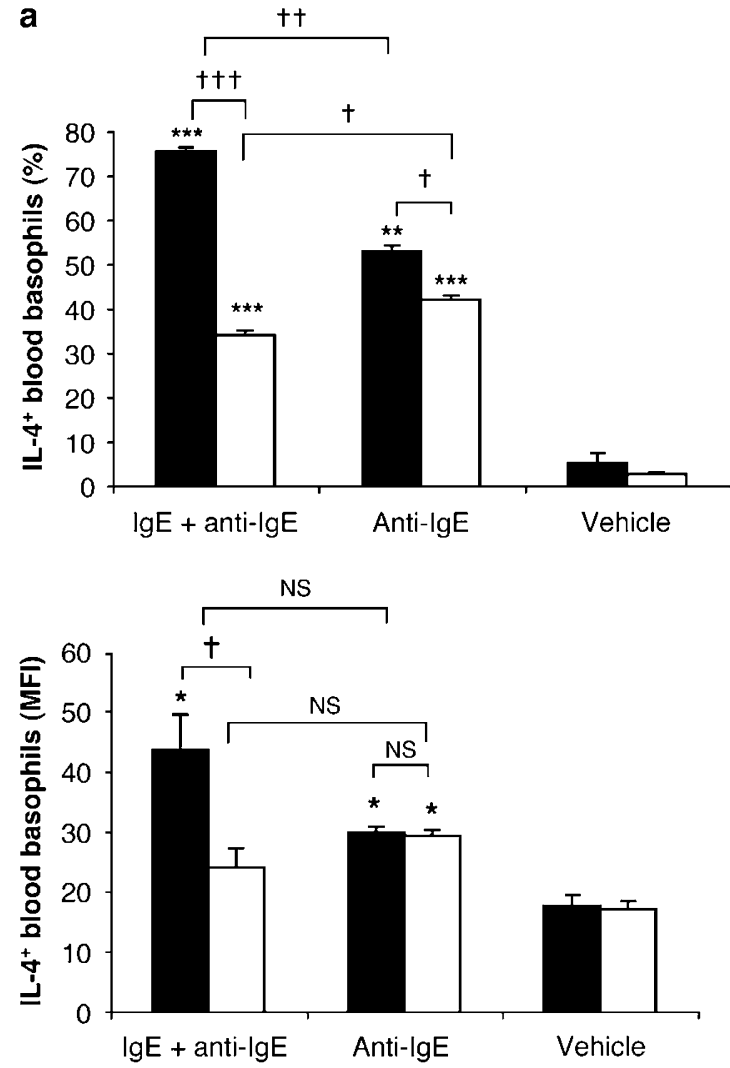

b
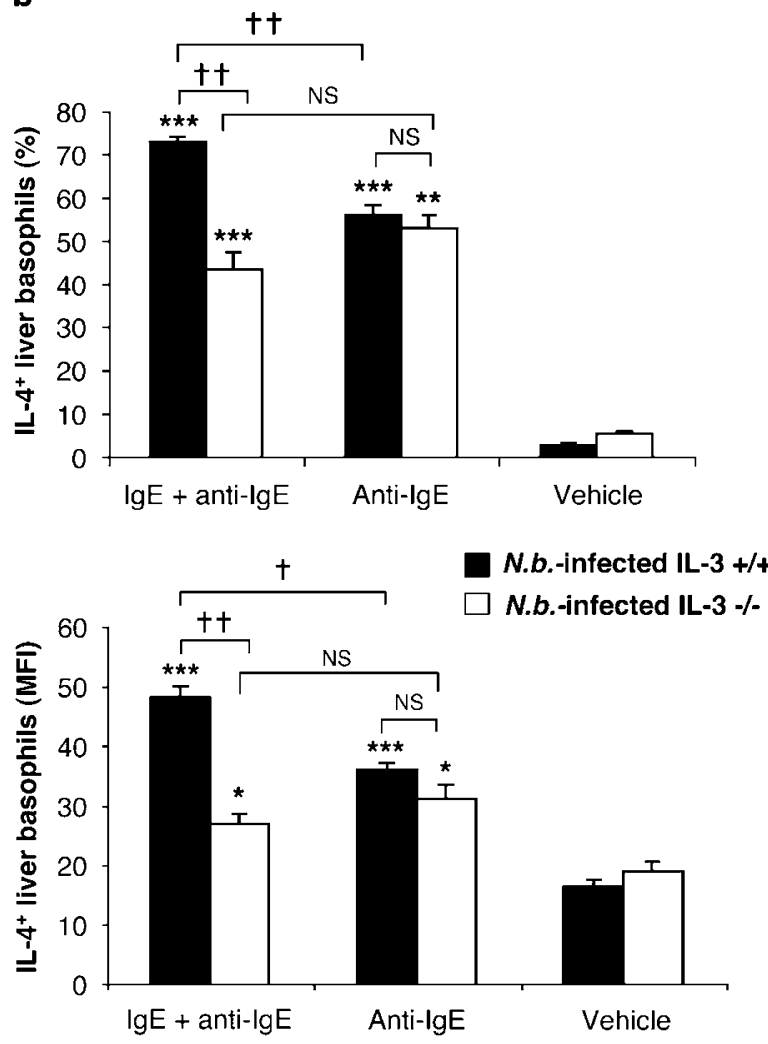

Figure 6 Enhanced production of intracellular IL-4 in blood basophils (a) or liver basophils (b) derived from BALB/c-IL-3 $3^{+/+} v s \mathrm{IL}-3^{-1-}$ mice after incubation with exogenous IgE and anti-lgE activation in vitro. On day 10 of infection, freshly isolated blood leukocytes (a) or liver cells (b) from N.b.-infected (500 larvae, subcutaneously) BALB/c-IL-3 $3^{+/+}$mice. Data in a are from two separate experiments, in each of which blood leukocytes were pooled from three to four mice of each genotype. Aliquots of the pooled cells (in experiment 1) or of two separate aliquots of the pooled cells (in experiment 2) were analyzed after treatment with or without exogenous IgE and with or without anti-lgE ex vivo ( $n=2-3$ values per treatment group). Data in $\mathbf{b}$ are from one experiment, which analysed liver cells from four IL-3 $3^{+/+}$mice and from three IL-3 $3^{-1-}$ mice. Cells in $\mathbf{a}$ and $\mathbf{b}$ were incubated on ice $\pm \mathrm{lgE}$ for $50 \mathrm{~min}$, followed by stimulation for $4 \mathrm{~h}$ at $37^{\circ} \mathrm{C}$ with anti-lgE mAb, the last $2 \mathrm{~h}$ in the presence of monensin. Basophils, identified as Fc $\mathrm{R}^{+}, \mathrm{CD} 45^{+}$cells, were examined for intracellular IL-4 production by FACS. The data are shown as $\%$ of basophils (mean \pm s.e.m.) that exhibit staining for intracellular IL-4 and MFI (mean \pm s.e.m.) of such IL-4 ${ }^{+}$basophils. ${ }^{*}$ indicates $P<0.05 ;{ }^{*} P<0.001$; and ${ }^{* * * P}<0.0001$ vs corresponding values for vehicle controls of the same genotype. ${ }^{\dagger}$ indicates $P<0.05 ;{ }^{\dagger \dagger} P<0.001 ;{ }^{\dagger \dagger} P<0.0001$ vs the values indicated by the square brackets. NS, not significant $(P>0.05)$.

When stimulated with anti-IgE in vitro in the presence of Brefeldin A (Figure 4) or monensin (Figure 5), blood or liverderived basophils from IL-3 ${ }^{-/-}$or IL- $3^{+/+}$mice exhibited substantial IL-4 production, as assessed by flow cytometric analysis of intracellular IL-4. By contrast, few blood or liver basophils derived from IL-3 ${ }^{-1-}$ or IL- $3^{+/+}$mice exhibited intracellular IL-4 after in vitro incubation for $4 \mathrm{~h}$ in the absence of anti-IgE stimulation (Figures 5 and 6). Similarly, blood or liver basophils examined by flow cytometry in cells freshly isolated from N.b.-infected IL- $3^{-1-}$ or IL- $3^{+/+}$mice exhibited little or no evidence of intracellular IL-4, nor did such mice exhibit differences in levels of serum IgE (data not shown).

These findings indicate that blood or liver basophils are capable of upregulating IL-4 production upon stimulation by IgE and anti-IgE, whether such basophils are derived from wild-type mice or mice that lack IL-3. It should be emphasized that our experiments used flow cytometry to examine intracellular IL-4 in basophils that had been stimulated by the FceRI ex vivo, and this approach may not be sensitive enough to detect what might be significant differences in the amounts of cytokines produced by various basophil populations that exhibit similar levels of intracellular IL-4 (eg, as in blood basophils derived from IL- $3^{-1-} v s$ IL-3 $3^{+/+}$mice that had been stimulated by anti-IgE in vitro in the absence of prior incubation with exogenous IgE).

However, when populations of blood or liver cells were incubated in vitro with exogenous IgE before their stimulation with anti-IgE, we found that blood or liver-derived basophils from IL-3 $3^{+/+}$mice exhibited substantially greater intracellular IL-4 responses than did identically treated basophils from IL- $3^{-l-}$ mice (Figures 5 and 6 ). These data are consistent with the conclusions of prior in vitro work indicating that IL-3 can significantly enhance FceRI-dependent production of IL-4 by cell populations in which basophils represent the most likely source of $\mathrm{IL}-4,{ }^{20}$ as well as 
FceRI-dependent activation and mediator secretion by mouse peritoneal mast cells ${ }^{21}$ and human blood basophils. ${ }^{22-24}$ Thus, even though our studies show that IL-3 is not required for basophil IL-4 production in response to challenge by the FceRI ex vivo, they also suggest that, at least under some circumstances, basophils derived from $\mathrm{IL}-3^{+/+}$mice can exhibit higher levels of IgE- and FceRI-dependent IL-4 production that do basophils from IL- $3^{-1-}$ mice.

\section{ACKNOWLEDGEMENTS}

We thank Fred Finkelman and William Paul and their colleagues for helpfu comments. Supported by NIH Grants AI23990, CA72074 and HL67674 to SJG, NIH Grant AI049932 and Jeffress Memorial Trust Grant J-782 to CSL, and startup funds from the Cleveland Clinic Foundation to BM; BM is the recipient of the career development grant from the American Heart Association.

1. Dvorak AM, Nabel G, Pyne K, et al. Ultrastructural identification of the mouse basophil. Blood 1982;59:1279-1285.

2. Seder RA, Paul WE, Dvorak AM, et al. Mouse splenic and bone marrow cell populations that express high-affinity Fc epsilon receptors and produce interleukin 4 are highly enriched in basophils. Proc Natl Acad Sci USA 1991;88:2835-2839.

3. Dvorak AM, Seder RA, Paul WE, et al. Effects of interleukin-3 with or without the c-kit ligand, stem cell factor, on the survival and cytoplasmic granule formation of mouse basophils and mast cells in vitro. Am J Pathol 1994;144:160-170.

4. Lantz CS, Boesiger J, Song $\mathrm{CH}$, et al. Role for interleukin-3 in mast-cell and basophil development and in immunity to parasites. Nature 1998;392:90-93.

5. Voehringer D, Shinkai K, Locksley RM. Type 2 immunity reflects orchestrated recruitment of cells committed to IL-4 production. Immunity 2004;20:267-277.

6. Galli SJ, Metcalfe DD, Arber DA, et al. Basophils and mast cells and their disorders. In: Lichtman MA, Beutler E, Kipps TJ, Seligsohn U, Kaushansky K, Prchal JT (eds). Williams Hematology, 7th edn. McGrawHill: New York, 2005, pp 879-897.

7. Mukai K, Matsuoka K, Taya C, et al. Basophils play a critical role in the development of IgE-mediated chronic allergic inflammation independently of T cells and mast cells. Immunity 2005;23:191-202.

8. Obata K, Mukai K, Tsujimura Y, et al. Basophils are essential initiators of a novel type of chronic allergic inflammation. Blood 2007;110:913-920.

9. Sokol CL, Barton GM, Farr AG, et al. A mechanism for the initiation of allergen-induced T helper type 2 responses. Nat Immunol 2008;9: 310-318.

10. Denzel A, Maus UA, Gomez MR, et al. Basophils enhance immunological memory responses. Nat Immunol 2008;9:733-742.

11. Kinet JP. The high-affinity IgE receptor (Fc epsilon RI): from physiology to pathology. Annu Rev Immunol 1999;17:931-972.

12. Marone G, Florio G, Petraroli A, et al. Human mast cells and basophils in HIV-1 infection. Trends Immunol 2001;22:229-232.
13. Marone G, Triggiani M, de Paulis A. Mast cells and basophils: friends as well as foes in bronchial asthma? Trends Immunol 2005;26:25-31.

14. Jacoby W, Cammarata PV, Findlay S, et al. Anaphylaxis in mast celldeficient mice. J Invest Dermatol 1984;83:302-304.

15. Paul WE, Seder RA, Plaut M. Lymphokine and cytokine production by Fc epsilon RI+ cells. Adv Immunol 1993;53:1-29.

16. Luccioli S, Brody DT, Hasan S, et al. $\lg E(+)$, kit(-), I-A/I-E(-) myeloid cells are the initial source of II- 4 after antigen challenge in a mouse model of allergic pulmonary inflammation. J Allergy Clin Immunol 2002;110:117-124.

17. Galli SJ, Franco CB. Basophils are back! Immunity. 2008;28: 495-497.

18. Tsujimura $\mathrm{Y}$, Obata $\mathrm{K}$, Mukai $\mathrm{K}$, et al. Basophils play a pivotal role in immunoglobulin-G-mediated but not immunoglobulin-E-mediated systemic anaphylaxis. Immunity 2008;28:581-589.

19. Prussin C, Metcalfe DD. 4. IgE, mast cells, basophils, and eosinophils. J Allergy Clin Immunol 2003;111:S486-S494.

20. Le Gros G, Ben-Sasson SZ, Conrad DH, et al. IL-3 promotes production of IL-4 by splenic non-B, non-T cells in response to Fc receptor crosslinkage. J Immunol 1990;145:2500-2506.

21. Coleman JW, Holliday MR, Kimber I, et al. Regulation of mouse peritoneal mast cell secretory function by stem cell factor, IL-3 or IL-4. J Immunol 1993;150:556-562.

22. Hirai K, Morita Y, Misaki $Y$, et al. Modulation of human basophil histamine release by hemopoietic growth factors. J Immunol 1988;141:3958-3964.

23. Miura K, MacGlashan Jr DW. Dual phase priming by IL-3 for leukotriene C4 generation in human basophils: difference in characteristics between acute and late priming effects. J Immunol 2000;164: 3026-3034.

24. Vilarino N, Miura K, MacGlashan Jr DW. Acute IL-3 priming up-regulates the stimulus-induced Raf-1-Mek-Erk cascade independently of IL-3-induced activation of Erk. J Immunol 2005;175:3006-3014.

25. Min B, Prout M, Hu-Li J, et al. Basophils produce IL-4 and accumulate in tissues after infection with a Th2-inducing parasite. J Exp Med 2004:200:507-517.

26. Shen T, Kim S, Do JS, et al. T cell-derived IL-3 plays key role in parasite infection-induced basophil production but is dispensable for in vivo basophil survival. Int Immunol 2008;20:1201-1209.

27. Khodoun MV, Orekhova T, Potter C, et al. Basophils initiate IL-4 production during a memory T-dependent response. J Exp Med 2004;200:857-870.

28. Mach N, Lantz CS, Galli SJ, et al. Involvement of interleukin-3 in delayed-type hypersensitivity. Blood 1998;91:778-783.

29. Lantz CS, Huff TF. Differential responsiveness of purified mouse c-kit+ mast cells and their progenitors to IL-3 and stem cell factor. J Immunol 1995:155:4024-4029.

30. Mack M, Schneider MA, Moll C, et al. Identification of antigen-capturing cells as basophils. J Immunol 2005;174:735-741.

31. Sampson JH, Archer GE, Ashley DM, et al. Subcutaneous vaccination with irradiated, cytokine-producing tumor cells stimulates CD8+ cellmediated immunity against tumors located in the "immunologically privileged" central nervous system. Proc Natl Acad Sci USA 1996;93:10399-10404. 